\title{
Biomarkers to detect membranous nephropathy in Chinese patients
}

\author{
Li Lin ${ }^{1}$, Wei Ming Wang ${ }^{1}$, Xiao Xia Pan ${ }^{1}$, Jing Xu ${ }^{1}$, Chen Ni Gao ${ }^{1}$, Wen Zhang ${ }^{1}$, Hong \\ Ren ${ }^{1}$, Jing Yuan Xie ${ }^{1}$, Pin Yan Shen ${ }^{1}$, Yao Wen $X_{u^{1}}{ }^{1}$,i Yan $N^{1}$ and Nan Chen \\ ${ }^{1}$ Department of Nephrology, Institute of Nephrology, Ruijin Hospital, School of Medicine, Shanghai Jiaotong University, \\ Shanghai, China
}

Correspondence to: Nan Chen, email: cnrj100@126.com

Keywords: chronic kidney disease, PLA 2 R, retinol binding protein, THSD7A, membranous nephropathy, Immunology and Microbiology Section, Immune response, Immunity

Received: June 17,2016 Accepted: September 05, $2016 \quad$ Published: September 13, 2016

\section{ABSTRACT}

Anti-M-type phospholipase $A_{2}$ receptor (anti-PLA $R$ ) is a widely accepted biomarker for clinical idiopathic membranous neurophathy (IMN). However, its ability to differentiate between IMN and secondary MN (SMN) is controversial. The objective of this study was to assess clinical MN biomarkers in blood, tissue and urine samples from Chinese patients. In total, $195 \mathrm{MN}$ patients and 70 patients with other glomerular diseases were prospectively enrolled in the study. Participants were followed up for average of 17 months (range 3-39 months). Anti-PLA $R$ and antiTHSD7A (thrombospondin type-1 domain-containing 7A) were detected only in MN patient sera and not in controls. Serum anti-THSD7A and THSD7A-positive biopsies were detected in 1/18 and 2/18 PLA $R$-negative MN cases, respectively. PLA $R$ and THSD7A were detected in $72.27 \%$ and $40 \%$ of SMN cases, respectively. While serum positivity for both anti-PLA 2 and anti-THSD7A at the time of renal biopsy was specific to $\mathrm{MN}$ patients, neither antigen could discriminate between primary and secondary MN. We also found that high urinary levels of retinol binding protein (RBP) predicted poor proteinuria outcomes in study participants. Patients with low or medium urinary RBP levels achieved remission more frequently than those with high RBP.

\section{INTRODUCTION}

Membranous nephropathy (MN) is the most common cause of nephrotic syndrome (NS) in Caucasian adults, accounting for $30-40 \%$ of cases [1]. In China, $\mathrm{MN}$ rates are increasing rapidly in patients with primary glomerular nephropathy, from $7.1 \%$ in 2000 to $22.7 \%$ in 2009-2011 [2]. MN is twice as common in men as in women, with a median age of onset in the early $50 \mathrm{~s}$ (39.64\%), and is the most common primary glomerular disease in patients over 60 years of age. The prevalence of $\mathrm{MN}$ in children is relatively low, accounting for less than $5 \%$ of biopsy diagnoses [3].

MN diagnosis conventionally relies on kidney biopsy. Approximately $75 \%$ of cases are idiopathic (IMN), with the remainder secondary to infection (e.g. hepatitis B), systemic autoimmune disease (e.g. lupus), medications (e.g. NSAIDs) and certain malignancies [46]. An IMN diagnosis is made by excluding secondary causes according to history, physical examination and appropriate laboratory tests, and by careful microscopic examination of the kidney biopsy. Previous studies showed that circulating autoantibodies against the M-type phospholipase $\mathrm{A}_{2}$ receptor (anti-PLA $\mathrm{R}_{2}$ ) are detectable in $52-82 \%$ of IMN patients and are absent or very uncommon in patients with secondary $\mathrm{MN}$ (SMN) [7-17]. As a result, anti-PLA $\mathrm{R}_{2}$ has been widely accepted as a biomarker for clinical IMN diagnosis due to its high sensitivity and specificity. However, anti-PLA ${ }_{2} \mathrm{R}$ might be detectable in certain SMN cases, such as tumor- and sarcoidosisassociated MN [10, 18]. In 2014, thrombospondin type-1 domain-containing 7A (THSD7A), another antigen similar to $\mathrm{PLA}_{2} \mathrm{R}$ in structure, was identified as a second potential IMN biomarker [19]. Approximately $8-14 \%$ of anti-PLA ${ }_{2} R$ seronegative patients had autoantibodies against THSD7A (anti-THSD7A) [19-21]. The incidence of THSD7Arelated MN was $13.63 \%$ in a European cohort and $8.18 \%$ in a Boston cohort in PLA 2 R-unrelated IMN [19]. Larsen reported a 3\% incidence of THSD7A-positive glomeruli in $\mathrm{MN}$ in the United States [21]. Iwakura reported this 
Table 1: PLA2R-related and -unrelated MN in SMN.

\begin{tabular}{|c|c|c|c|c|c|c|c|c|c|c|c|c|c|c|}
\hline & $\begin{array}{l}\text { Hepatitis B } \\
(N=11)\end{array}$ & $\begin{array}{l}\text { Hepatitis } \\
\text { C } \\
(N=1)\end{array}$ & $\begin{array}{l}\text { Syphilis } \\
(N=2)\end{array}$ & $\begin{array}{l}\text { Tumor } \\
(N=9)\end{array}$ & $\begin{array}{l}\text { Psoriasis } \\
(N=3)\end{array}$ & $\begin{array}{l}\text { Sjögren's } \\
\text { syndrome } \\
(N=2)\end{array}$ & \begin{tabular}{|l} 
Guillain- \\
Barre \\
syndrome \\
$(N=1)$
\end{tabular} & $\begin{array}{l}\text { Amyloidosis } \\
(N=1)\end{array}$ & $\begin{array}{l}\text { Monoclonal } \\
\text { gammopathy } \\
(N=1)\end{array}$ & $\begin{array}{l}\text { Interstitial } \\
\text { nephritis } \\
(N=3)\end{array}$ & $\begin{array}{l}\text { DN } \\
(N=2)\end{array}$ & $\begin{array}{l}\text { Familial } \\
(N=2)\end{array}$ & $\begin{array}{l}\text { IMN } \\
(N=99)\end{array}$ & $\begin{array}{l}\text { Type V LN } \\
(N=18)\end{array}$ \\
\hline $\begin{array}{l}\text { PLA2R- } \\
\text { related } \\
\mathrm{MN}(n=118)\end{array}$ & 9 & 1 & 1 & 5 & 2 & 0 & 0 & 1 & 1 & 3 & 2 & 2 & 92 & 0 \\
\hline $\begin{array}{l}\text { Anti- } \\
\text { PLA_R(+) } \\
\text { by IFA (n) } \\
\end{array}$ & 9 & 1 & 1 & 3 & 2 & 0 & 0 & 1 & 1 & 3 & 2 & 2 & 71 & 0 \\
\hline $\begin{array}{l}\text { Average } \\
\text { titer of anti- } \\
\text { PLA R } \\
(\mathrm{RU} / \mathrm{ml})\end{array}$ & 241 & 184 & 200 & 204 & 85 & 0 & 1 & 400 & 41 & 598 & 123 & 329 & 154 & I \\
\hline $\begin{array}{l}\operatorname{PLAR}(+) \text { in } \\
\text { glomeruli (n) }\end{array}$ & 8 & 1 & 1 & 5 & 2 & 0 & 0 & 1 & 1 & 3 & 2 & 2 & 89 & 0 \\
\hline $\begin{array}{l}\text { PLA R- } \\
\text { unrelated } \\
\mathrm{MN}(n=18)\end{array}$ & 2 & I & 1 & 4 & 1 & 2 & 1 & I & 1 & 1 & 1 & I & 7 & 18 \\
\hline $\begin{array}{l}\text { Average } \\
\text { titer of anti- } \\
\text { PLA R } \\
(\mathrm{RU} / \mathrm{ml})\end{array}$ & $<0$ & I & 0 & 1 & 6 & 1 & 0 & 1 & 1 & 1 & 1 & I & 0.1 & I \\
\hline
\end{tabular}

18 patients with class V LN included: LN-V $(n=1), \mathrm{LN}-\mathrm{IV}+\mathrm{V}(\mathrm{n}=10), \mathrm{LN}-\mathrm{III}+\mathrm{V}(\mathrm{n}=7)$.

as $9.1 \%$ in Japanese [20]. However, the usefulness of $\mathrm{PLA}_{2} \mathrm{R}$ and THSD7A has not yet been assessed in Chinese $\mathrm{MN}$ patients. In addition, the prognostic values of low molecular weight (LMW) proteins in MN patient urine must be validated in different populations [22-24].

Here, we report anti-PLA 2 and anti-THSD7A serum levels, and $\mathrm{PLA}_{2} \mathrm{R}$ and THSD7A staining in glomeruli of $\mathrm{MN}$ patients. We compared clinical parameters, pathological features and clinical outcomes between PLA 2 R-positive and -negative MN cohorts. Moreover, this study evaluated the utility of urinary LMW proteins as predictors of proteinuria outcome. To relate clinical characteristics to baseline anti-PLA 2 R and antiTHSD7A levels at the time of renal biopsy, and to prove whether the titer of anti-PLA 2 , urinary LMW proteins, including urinary $\beta 2$ microglobulin $(\beta 2 \mathrm{~m})$, urinary $\alpha 1$ microglobulin $(\alpha 1 \mathrm{~m})$, the urinary retinol binding protein (RBP) and urinary N-Acetyl- $\beta$-D-indiglucosaminidase (NAG) affect disease outcome. This is the first study to objectively assess the diagnostic and prognostic values of blood, urine and kidney biomarkers in Chinese $\mathrm{MN}$ patients.

\section{RESULTS}

\section{$\mathrm{PLA}_{2} \mathrm{R}$ in $\mathrm{MN}$ diagnosis}

A total of 315 subjects were recruited for this study, including 195 renal biopsy-confirmed MN patients. Serum samples were collected from 54 of these patients crosssectionally after treatments (Figure 1). The remaining 141 patients did not receive any $\mathrm{MN}$-specific treatments. We also tested 70 patients with non-MN diseases and 50 healthy controls. Anti-PLA 2 R and anti-THSD7A were only found in patients with $\mathrm{MN}$, and were not detected in either healthy controls or non-MN patients (Figure 2 $\&$ S1). Among the non-MN patients, 18 out of 21 lupus nephropathy (LN) patients with class $\mathrm{V}$ disease (1 LN-V, $10 \mathrm{LN}-\mathrm{IV}+\mathrm{V}, 7 \mathrm{LN}-\mathrm{III}+\mathrm{V})$ were negative for circulating anti-PLA 2 R/anti-THSD7A and glomeruli PLA 2 / THSD7A.

Of the $54 \mathrm{MN}$ patients whose serum was sampled cross-sectionally, 23 had circulating anti-PLA2R antibodies. Anti-PLA 2 R was detected in $8.33 \%$ of complete remission (CR) patients, $31.58 \%$ of partial remission (PR) patients and $69.57 \%$ of no remission patients $(P=0.001)$ (Table S1, Figure S3).

Of the patients who were followed up longitudinally $(n=136)$, the majority of PLA 2 R-related MN patients were men $(58.87 \%)$, aged 15 to 83 (median $=39.8)$. Positive serum anti-PLA 2 R and glomerular $\mathrm{PLA}_{2} \mathrm{R}$ rates were $69.50 \%$ and $83.21 \%$, respectively, in this population (Figure S1 \& S2). The rate of PLA R-related MN was 87.23\%. In $37 \mathrm{SMN}$ cases, $72.27 \%$ were PLA 2 R-related MN (Figure 3A), and the anti-PLA $R$ titer was $217 \pm 291$ $\mathrm{RU} / \mathrm{ml}$ (Table 1). In the remaining 99 patients, the rate of $\mathrm{PLA}_{2} \mathrm{R}$-related $\mathrm{MN}$ was $92.92 \%$ (Figure $3 \mathrm{~B}$ ), and the anti-PLA 2 R titer was $154 \pm 255 \mathrm{RU} / \mathrm{ml}$ (Table 1). More SMN patients exhibited PLA R-unrelated than PLA Rrelated $\mathrm{MN}$ ( $61.11 \%$ vs $21.13 \% P=0.01$ ) (Figure $3 \mathrm{C}$ 3D). $56 \%$ of tumor-associated MN was PLA R-related. $50-82 \%$ of $\mathrm{MN}$ secondary to infection (HBV-, HCV- and syphilis-associated $\mathrm{SMN}$ ) was $\mathrm{PLA}_{2} \mathrm{R}$-related. $\mathrm{PLA}_{2} \mathrm{R}$ was also detected in other SMN patients, including those with psoriasis-, monoclonal gammopathy-, interstitial nephritis-, diabetes nephropathy- and hereditaryassociated MN (Figure 3E, Table 1).

Patients with circulating anti-PLA $\mathrm{A}_{2} \mathrm{R}$ and with $\mathrm{PLA}_{2} \mathrm{R}$ deposits in glomeruli were included in group 1 , 
Table 2: Clinical features, baseline PLA2R levels and outcomes in PLA,R-related and -unrelated MN.

\begin{tabular}{|c|c|c|c|c|c|c|}
\hline \multirow{2}{*}{ Clinical features } & \multirow{2}{*}{$\begin{array}{l}\text { GROUP1(PLA } R+ \\
\left.\text { anti-PLA }_{2} R+\right)\end{array}$} & \multirow{2}{*}{$\begin{array}{l}\text { GROUP2(PLA } \mathbf{A}_{2} \mathbf{R} \\
+ \\
\left.\text { anti-PLA }_{2} R-\right)\end{array}$} & \multirow{2}{*}{$\begin{array}{l}\text { GROUP3(PLA R - } \\
\text { anti-PLA } 2 \text { R +) }\end{array}$} & \multirow{2}{*}{$\begin{array}{l}\text { GROUP4(PLA } A_{2} R- \\
\text { anti-PLA } 2 \text { - }\end{array}$} & & \multirow[b]{2}{*}{$\begin{array}{l}\text { GROUP1 } \\
\text { and } 2\end{array}$} \\
\hline & & & & & GROUP1-4 & \\
\hline \multicolumn{7}{|l|}{ Index at baseline $\quad(n=136)$} \\
\hline Number of patients & $89(65.44)$ & $24(17.64)$ & $5(3.68)$ & $18(13.24)$ & / & / \\
\hline $\operatorname{Sex}(M \%)$ & $52(58.42)$ & $13(58.33)$ & $3(60.00)$ & $11(61.11)$ & 0.972 & 0.441 \\
\hline Age (year) & $59(15-83)$ & $54.5(23-77)$ & $46(25-66)$ & $55(17-79)$ & 0.524 & 0.276 \\
\hline $\begin{array}{l}\text { Anti-PLA } \mathrm{R}_{2} \text { assay from } \\
\text { on set (month) }\end{array}$ & $2(0.25-180)$ & $1.5(0.25-12)$ & $2(1-24)$ & $3.5(0.25-12)$ & 0.284 & 0.135 \\
\hline IS use before assay( $\%)$ & $4(4.49)$ & $0(0)$ & $0(0)$ & $1(5.56)$ & 0.693 & 0.379 \\
\hline 24h-Proteinuria (g/24) & $5.43(0.59-21.02)$ & $3.52(0.49-6.92)$ & $12.33(5.02-25.78)$ & $5.00(0.68-22.98)$ & $0.001 *$ & 0.001 \\
\hline Albumin (g/l) & $21(10-39)$ & $24(16-35)$ & $14(13-23)$ & $24(11-35)$ & $0.022 *$ & 0.042 \\
\hline Serum creatinine (umol/l) & $68(23-262)$ & $65(42-120)$ & $63(58-97)$ & $75.5(51-160)$ & 0.473 & 0.234 \\
\hline $\operatorname{GFR}\left(\mathrm{ml} / \mathrm{min} / 1.73 \mathrm{~m}^{2}\right)$ & $108(22-151)$ & $114(57-150)$ & $113(71-131)$ & $104(38-135)$ & 0.473 & 0.131 \\
\hline Nephrotic syndrome (\%) & $72(80.90)$ & $12(50)$ & $5(100)$ & $13(72.22)$ & $0.01 *$ & 0.003 \\
\hline Follow-up(month) & $17(3-39)$ & $14(3-39)$ & $28(8-34)$ & $19(3-33)$ & 0.423 & 0.355 \\
\hline \multicolumn{7}{|l|}{ Index of outcome $(n=99)$} \\
\hline Number of patients & 68 & 13 & 4 & 14 & / & / \\
\hline Disease active $(\%)$ & $17(25.00)$ & $2(15.38)$ & $1(25)$ & $1(7.15)$ & \multirow{3}{*}{0.687} & \multirow{3}{*}{0.07} \\
\hline Partial remission( $(\%)$ & $27(39.71)$ & $6(46.16)$ & $2(50)$ & $5(35.71)$ & & \\
\hline Completely remission( $\%)$ & 24(35.29) & $5(38.46)$ & $1(25)$ & $8(57.14)$ & & \\
\hline Time to PR(week) & $2(0.25-18)$ & $2.5(0.25-15)$ & $4(2-4.25)$ & $4(1-21)$ & 0.305 & 0.258 \\
\hline GFR $>25 \%$ & $2(2.25)$ & 0 & 0 & 0 & / & I \\
\hline
\end{tabular}

Group 1, serum anti- PLA R - and glomerular PLA R -positive patients; Group 2, glomerular PLA R -positive but serum anti- PLA 2 R -negative patients; Group 3, serum anti- PLA R -positive but glomerular PLA 2 R -negative patients; and Group 4 , serum anti- PLA 2 -negative and glomerular PLA $R$-negative patients.

IS: Immunosuppressor. "*”: $P$ value $<0.05$ was considered as statistical significance.

patients negative for circulating anti-PLA 2 , but with $\mathrm{PLA}_{2} \mathrm{R}$ in glomerular deposits were included in group 2, patients positive for circulating anti-PLA $\mathrm{A}_{2} \mathrm{R}$, but negative for $\mathrm{PLA}_{2} \mathrm{R}$ in glomerular deposits were included in group 3 and patients negative for both circulating anti-PLA $R$ antibodies and $\mathrm{PLA}_{2} \mathrm{R}$ in glomeruli were included in group 4. There were $89(65.44 \%), 24(17.64 \%), 5(3.68 \%)$ and $18(13.24 \%)$ patients in groups 1, 2, 3 and 4, respectively (Table 2). Cases in the group 1 had a mean 24-h proteinuria of $5.43 \mathrm{~g}$. This was higher than $3.52 \mathrm{~g}$, the mean 24-h proteinuria level for cases in the group 2 . There was no statistical difference in sex, age, time at renal biopsy from onset or follow-up time between $\mathrm{PLA}_{2} \mathrm{R}$-related and
$\mathrm{PLA}_{2} \mathrm{R}$-unrelated MN patients. Furthermore, there was no significant difference in any relevant clinical parameters, such as serum creatinine (Scr) or glomerular filtration rate (GFR), among the four groups. More anti-PLA 2 Rpositive patients developed nephrotic-range proteinuria $(80.90 \%)$ than did anti-PLA 2 R-negative patients $(50.00 \%$, $P=0.003)$. All $136 \mathrm{MN}$ biopsies were analyzed for the extent of tubulointerstitial fibrosis and glomerular lesions. Interstitial fibrosis was found in 117 of 136 specimens. There were no significant differences in the percentage of patients with interstitial fibrosis, glomerular lesions or segmental glomerulosclerosis among the four groups (Table 3). 


\section{THSD7A in MN diagnosis}

Of 136 patients, 2 patients stained positive for glomerular THSD7A via immunohistochemical analysis (Figure 4A-4D). Serum anti-THSD7A was detected in one of these patients via western blotting (Figure 4E). Both of the THSD7A-related MN patients were negative for glomerular PLA ${ }_{2}$ and serum anti-PLA $R$. No patient exhibited dual positivity for $\mathrm{PLA}_{2} \mathrm{R}$ and THSD7A.
In THSD7A-related $\mathrm{MN}$, the ratio of females to males was 0.667. Patient ages ranged from 24 to 62 , and $40 \%$ had nephrotic syndrome at the time of renal biopsy (Table 4). $40 \%$ of THSD7A-related MN was secondary to thyroid tumor or HBV infection. Histologic and biochemical THSD7A-related MN characteristics resembled those of PLA R-related MN. During followup (2-24 months), $80 \%$ of THSD7A-related MN patients achieved remission (CR or PR)(Table 4).

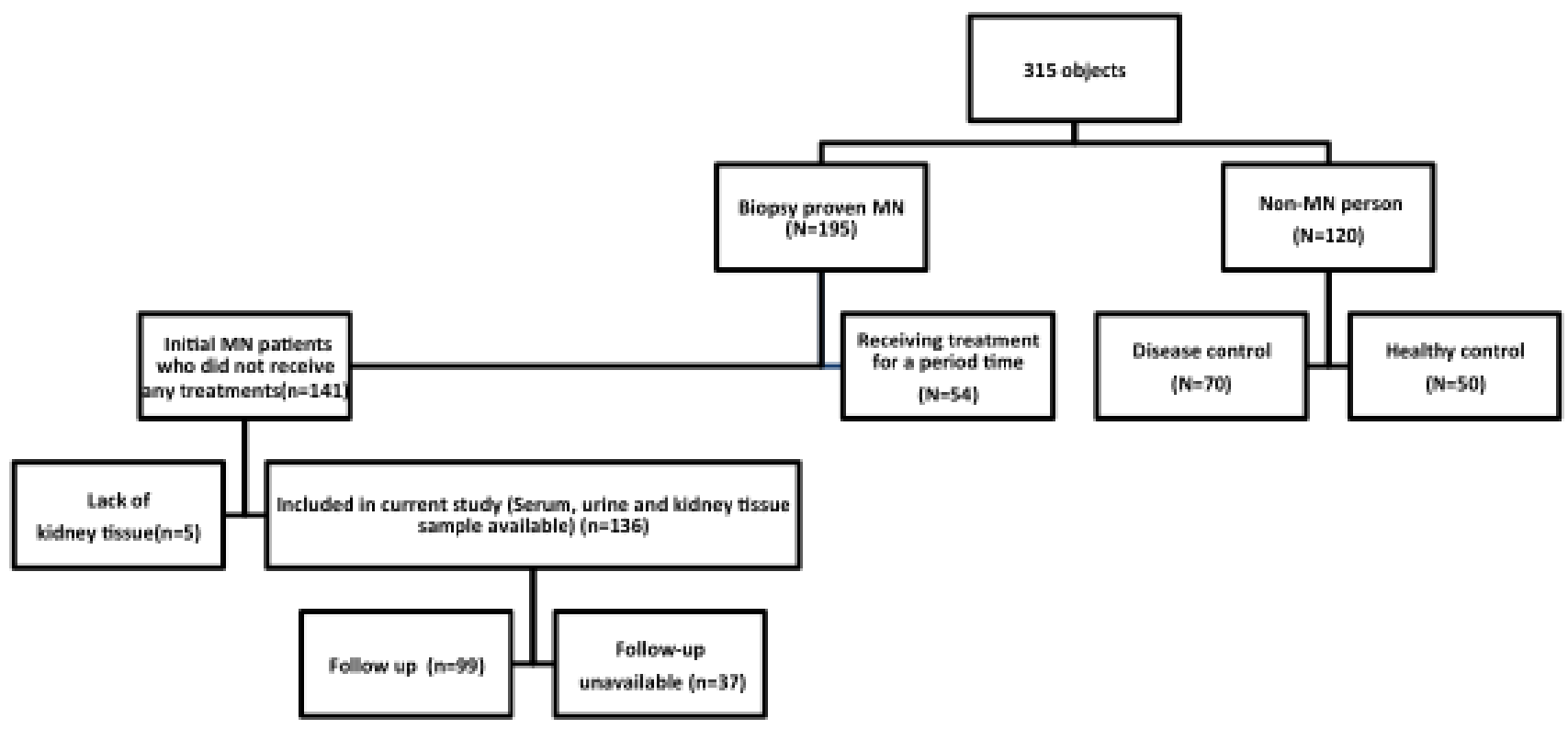

Figure 1: Patient recruitment parameters and inclusion flowchart.

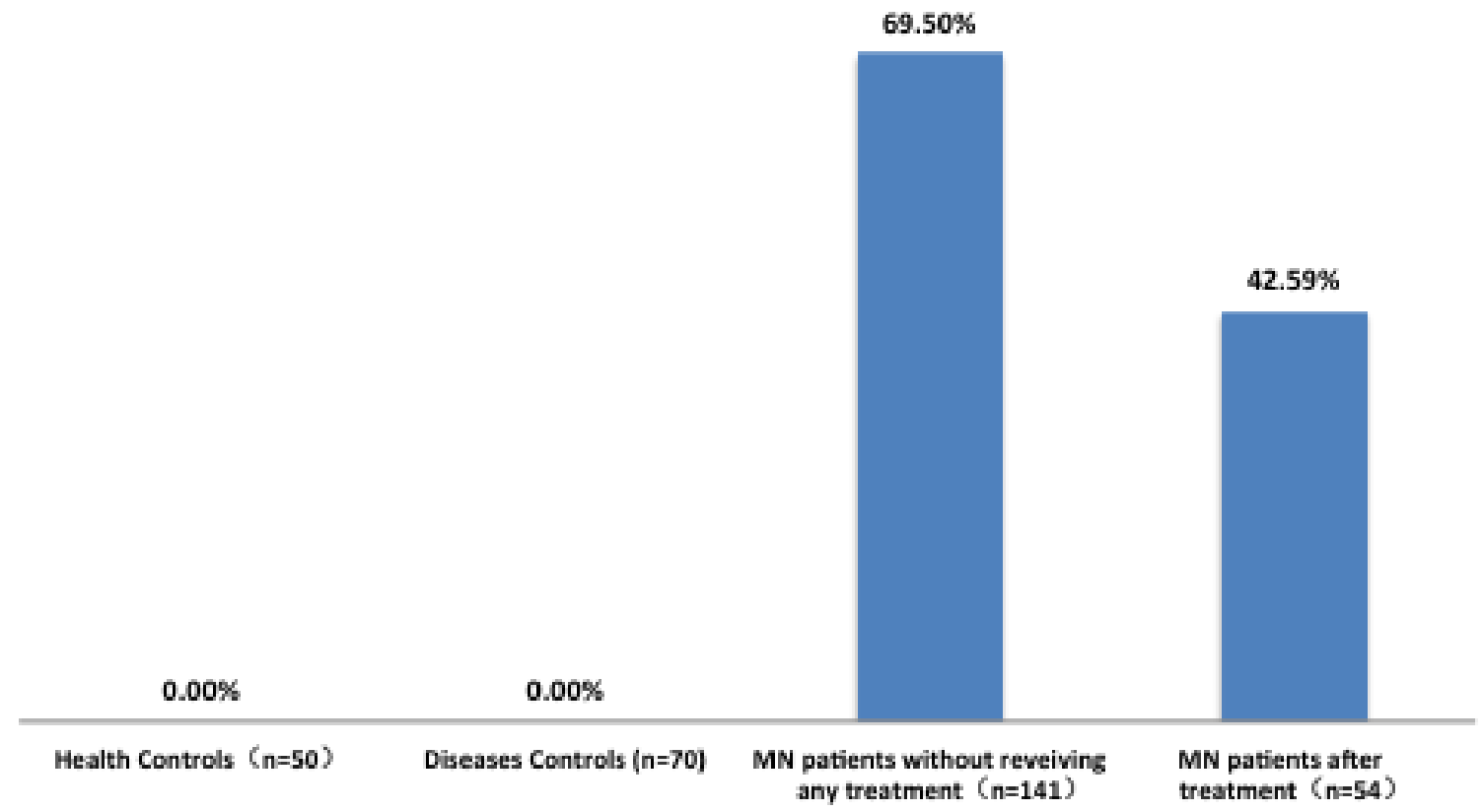

Figure 2: Rates of serum anti-PLA $\mathbf{R}$ positivity in patients and controls. Disease controls: IgA nephropathy $(n=5)$, minimal change disease $(n=11)$, focal segmental glomerular sclerosis $(n=10)$, membrano-proliferative glomerulonephritis $(n=6)$, lupus nephropathy ( $n=21$, including $1 \mathrm{LN}-\mathrm{III}, 2 \mathrm{LN}-\mathrm{IV}, 1 \mathrm{LN}-\mathrm{V}, 10 \mathrm{LN}-\mathrm{IV}+\mathrm{V}, 7 \mathrm{LN}-\mathrm{III}+\mathrm{V})$, ANCA-associated vasculitis $(n=5)$, amyloidosis $(n=3)$, lymphoma $(n=1)$, Goodpasture syndrome $(n=1)$, diabetic nephropathy $(n=1)$ and ANA(autoantibody to nuclear antigen) $(+)$ of unknown significance $(n=50)$. 
Table 3: Renal biopsy findings $(n=136)$

\begin{tabular}{|c|c|c|c|c|c|}
\hline Histologic characteristics & $\begin{array}{l}\text { GROUP1(PLA_R + } \\
\text { anti-PLA } R+)_{2}\end{array}$ & $\begin{array}{l}\text { GROUP2(PLA } R+ \\
\text { anti-PLA } R-\text { R-) }\end{array}$ & $\begin{array}{l}\text { GROUP3(PLA } R \text { R - } \\
\text { anti-PLA } 2 \text { R +) }\end{array}$ & $\begin{array}{l}\text { GROUP4(PLA } A_{2} R \text { - } \\
\text { anti-PLA } 2 \text { R -) }\end{array}$ & $P$ value \\
\hline Number of patients & 89 & 24 & 5 & 18 & \\
\hline \multicolumn{6}{|c|}{ Glomerular lesions (electron microscopy) \% } \\
\hline $\mathrm{I}(\%)$ & $19(22.09)$ & $7(19.17)$ & $0(0)$ & $6(33.33)$ & \multirow{3}{*}{0.795} \\
\hline $\mathrm{II}(\%)$ & $52(60.47)$ & $14(58.33)$ & $4(80)$ & $9(50)$ & \\
\hline $\operatorname{III}(\%)$ & $14(16.28)$ & $3(12.50)$ & $1(20)$ & $3(16.67)$ & \\
\hline \multicolumn{6}{|l|}{ Interstitial fibrosis (\%) } \\
\hline None & $13(14.94)$ & $5(20.83)$ & $0(0)$ & $1(5.56)$ & \multirow{3}{*}{0.840} \\
\hline Minor & $75(84.27)$ & $19(79.17)$ & $5(100)$ & $13(94.44)$ & \\
\hline Moderate & $1(1.12)$ & $0(0)$ & $0(0)$ & $0(0)$ & \\
\hline Focal segmental sclerosis & $11(12.36)$ & $1(4.17)$ & $1(20)$ & $1(5.56)$ & 0.506 \\
\hline IgG4 + (\%) & 100 & 100 & 100 & 55.56 & $<0.001$ \\
\hline
\end{tabular}

Interstitial fibrosis minor $:<25 \%$ of the tubulointerstitial space involved, moderate $:>25 \%$ but $<50 \%$ of the tubulointerstitial space involved, extensive : $>50 \%$ of the tubulointerstitial space involved
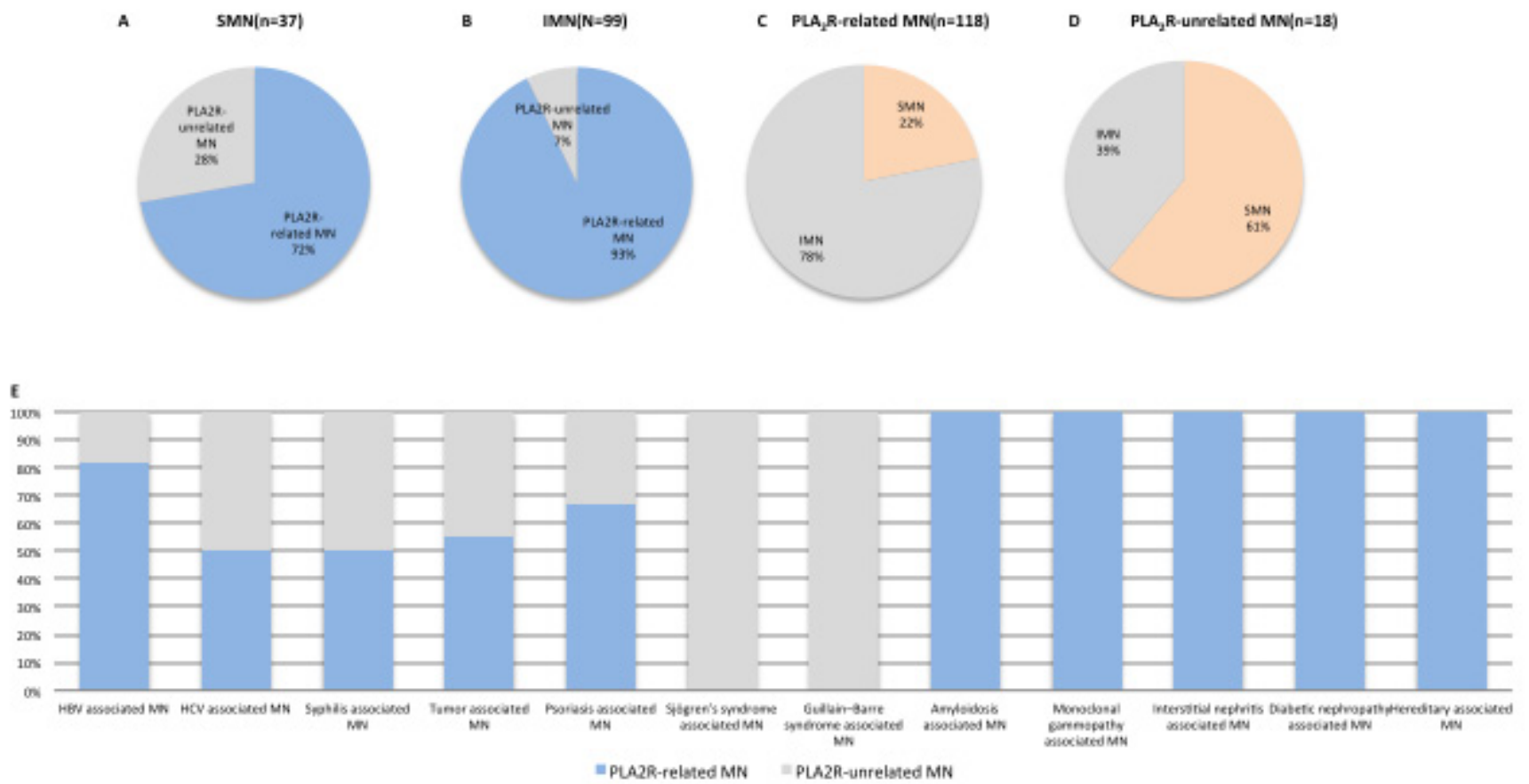

Figure 3: PLA 2 R in SMN. PLA 2 R positivity rates in SMN A. and IMN B. SMN rate in PLA R-related MN C. and PLA R-unrelated MN D. PLA R-related MN in SMN E. Secondary MN associations: hepatitis B, $n=11$; hepatitis C, $n=1$; syphilis, $n=2$; tumor, $n=8$; psoriasis, $n=3$; Sjögren's syndrome, $n=2$; Guillain-Barre syndrome, $n=1$; amyloidosis, $n=1$; monoclonal gammopathy, $n=1$; interstitial nephritis, $n=2$; diabetic nephropathy, $n=2$; hereditary $\mathrm{MN}, n=2$; hepatitis B and tumor, $n=1$. Tumor-associated MN: Laryngocarcinoma, $n=1$; lymphoma $n=1$; rectal carcinoma, $n=1$; mediastinal tumor, $n=1$; breast cancer, $n=1$; lung cancer, $n=1$; thyroid tumor, $n=1$; gynecological cancer, $n=1$. 
Table 4: Clinical features at baseline and outcome in THSD7A-related MN

\begin{tabular}{|c|c|c|c|c|c|c|c|c|c|c|c|c|c|c|}
\hline & \multicolumn{3}{|c|}{ Clinical features } & \multicolumn{2}{|l|}{ THSD7A } & \multicolumn{3}{|c|}{ Histologic characteristics } & \multicolumn{4}{|c|}{ Biochemical index at baseline } & \multicolumn{2}{|c|}{ Index of outcome } \\
\hline Number & Gender & Age(yr) & SMN or IMN & \begin{tabular}{|l} 
Serum \\
anti- \\
THSD7A
\end{tabular} & $\begin{array}{l}\text { Glomeruli } \\
\text { THSD7A }\end{array}$ & $\begin{array}{l}\text { Glomerular } \\
\text { lesions }\end{array}$ & $\begin{array}{l}\text { Interstitial } \\
\text { fibrosis }\end{array}$ & \begin{tabular}{|l} 
Glomeluli \\
IgG4
\end{tabular} & $\begin{array}{l}\text { 24h-proteinuria } \\
\text { (g/24h) }\end{array}$ & \begin{tabular}{|l} 
Alb \\
$(\mathrm{g} / \mathrm{I})$
\end{tabular} & \begin{tabular}{|l} 
Scr \\
$(\mathrm{mmol} / \mathrm{L})$
\end{tabular} & \begin{tabular}{|l|} 
GFR \\
$(\mathrm{ml} /$ \\
$\mathrm{min} / 1.73 \mathrm{~m} 2)$
\end{tabular} & $\begin{array}{l}\text { Follow- } \\
\text { up } \\
\text { (month) }\end{array}$ & $\begin{array}{l}\text { proteinuria } \\
\text { outcome }\end{array}$ \\
\hline Patient 1 & Male & 46 & $\begin{array}{l}\text { tumor } \\
\text { associated } \\
\text { MN } \\
\end{array}$ & - & + & MN-I & Minor & + & 6.356 & 18 & 63 & 126.40 & 24 & CR \\
\hline Patient 2 & Male & 62 & $\begin{array}{l}\text { HBV } \\
\text { associated } \\
\text { MN }\end{array}$ & + & + & MN-1 & Minor & + & 5.619 & 19 & 65 & 114.75 & 13 & NR \\
\hline Patient 3 & Female & 35 & IMN & + & + & MN-II & Minor & + & 1.482 & 28 & 53 & 137.54 & 8 & $\mathrm{CR}$ \\
\hline Patient 4 & Female & 24 & IMN & - & + & MN-II & Minor & + & 2.993 & 24 & 50 & 120.68 & 3 & $\mathrm{CR}$ \\
\hline Patient 5 & Female & 32 & IMN & + & + & MN-II & Minor & + & 2.819 & 32 & 61 & 120 & 4 & PR \\
\hline
\end{tabular}

Patient 1 and patient 2 from this study, patients 3-5 from the following study

Table 5: Disease status at the end of follow-up in three groups divided by RBP/creatinine (mg/mmol) at baseline

\begin{tabular}{|l|l|l|l|l|}
\hline Group & Duration(month) & Complete remission(\%) & Partial remission(\%) & No remission(\%) \\
\hline Low level $(<0.1941)$ & $14(3-39)$ & 40.63 & 40.63 & 18.74 \\
\hline Medium level(0.1941-0.4772) & $16(3-36)$ & 34.38 & 59.38 & 6.24 \\
\hline High level $>0.4772)$ & $18(3-36)$ & 45.16 & 16.13 & 38.71 \\
\hline$P$ value & 0.659 & 0.003 & & \\
\hline
\end{tabular}

\section{$\mathrm{PLA}_{2} \mathrm{R}$ as a prognostic biomarker for MN}

99 patients remained at the end of the follow-up period and were classified as in remission $(n=78)$ or no remission $(n=21)$. Follow-up times for these two groups averaged 17 (3-39) and 13 months (3-36), respectively $(P=0.154)$. During the study, only two patients had an increase in Scr by $\geq 25 \%$ and GFR $\leq 60 \mathrm{ml} / \mathrm{min} / 1.73 \mathrm{~m}^{2}$.

In group 1, 17 (25\%) patients still had active disease at the end of the follow-up period, $24(35.29 \%)$ were in $\mathrm{CR}$, and 27 (39.71\%) were in PR. In group 2, $6(46.16 \%)$ patients were in PR and $5(38.46 \%)$ were in CR. In group $3,1(25 \%)$ patient was in CR and $2(50 \%)$ were in PR. In group 4, 8 (57.14\%) patients were in CR and 5 (35.71\%) were in PR (Table 1). Remission rate was the same among the four groups $(P=0.687)$, and the time to achieving PR in anti-PLA 2 R-positive patients was similar to that of anti$\mathrm{PLA}_{2} \mathrm{R}$-negative patients $(P=0.258)$ (Table 2$)$.

The baseline anti-PLA 2 R titer in the no remission group was much higher than in the remission group $(P$ $=0.0035$ ). The anti-PLA 2 R titer AUC (area under ROC curve) was 0.751 when anti-PLA 2 titer at the time of renal biopsy was assessed as a predictor of no remission (Figure 5). Patients were divided into three groups based on anit-PLA 2 R titer. Anti-PLA 2 R levels $<29.76 \mathrm{RU} / \mathrm{ml}$ were included in tertile 1 (low titer), 29.76-98.82 RU/ml in tertile 2 (medium titer) and $>98.829 \mathrm{RU} / \mathrm{ml}$ tertile 3 (high titer). There was no difference in remission rate among the three groups $(P=0.130)$. A Cox model indicated that baseline anti-PLA 2 R level was not associated with disease activity, adjusting for the effects of all other variables.

\section{LMW proteins as biomarkers to predict MN prognosis}

When assessing urinary LMW proteins as predictors of no remission, urinary $\alpha 1 \mathrm{~m}, \beta 2 \mathrm{~m}, \mathrm{RBP}$ and NAG AUCs were $0.370,0.394,0.740$ and 0.331 , respectively (Figure $5 \mathrm{~A})$. When corrected by urinary creatinine $(\mathrm{Cr}), \mathrm{ROCs}$ were as follows: $\alpha 1 \mathrm{~m} / \mathrm{Cr} 0.483, \beta 2 \mathrm{~m} / \mathrm{Cr} 0.495, \mathrm{RBP} / \mathrm{Cr}$ $0.778, \mathrm{NAG} / \mathrm{Cr} 0.445$ (Figure 5B). Patients were divided into three groups based on baseline RBP/Cr. 38.71\% of patients in the high $\mathrm{RBP} / \mathrm{Cr}$ group had not achieved remission by the end of the follow-up period, while only $18.74 \%$ and $6.24 \%$ of patients in the low and medium level groups, respectively, had not achieved remission $(P$ $=0.003)($ Table 5). 


\section{DISCUSSION}

This prospective study assessed Chinese patient blood, kidney tissue and urine samples to identify new MN biomarkers for clinical application, and to assess existing biomarkers. Our results showed that serum anti$\mathrm{PLA}_{2} \mathrm{R}$ and anti-THSD7A specificities for MN diagnosis were both $100 \%$, and sensitivities were $42.59-69.5 \%$ and $1.47 \%$, respectively. As a non- inflammatory autoimmune disease, MN affected affecteds the kidney glomerulus, resulting in the formation of immune deposits on the outer aspect of the glomerular basement membrane [1]. The binding of circulating antibodies specific for an intrinsic antigen presented on the basal surface of the podocytes is the mechanism at play in most forms of adult $\mathrm{MN}$ [25]. THSD7A and PLA 2 R exhibit similar structural and biochemical properties [19, 21, 26]. These two antigens are both located in podocytes, and autoantibodies against both are predominantly classified into the IgG4 subclass $[7,19]$. A number of molecular biological and genetics studies have shown that $\mathrm{PLA}_{2} \mathrm{R}$ plays an important role in MN [8-11, 13, 27-30]. The dominant humoral epitope is in the N-terminal region of $\mathrm{PLA}_{2} \mathrm{R}$ and is recognized by $90 \%$ of human anti-PLA2R autoantibodies [15, 31]. Moreover, the epitope (9-amino acid peptide within the 31-mer) itself is capable of inhibiting $47 \%$ of binding shares homology with a bacterial enzyme, thus invoking molecular mimicry as a potential initiator of autoimmunity [31]. In addition, genome-wide association studies (GWAS) revealed significant associations between the 6p21 HLA- DQA1 and $2 \mathrm{q} 24 \mathrm{PLA}_{2} \mathrm{R}$ loci with $\mathrm{MN}$ in European patients [29], which was confirmed in populations from Asia

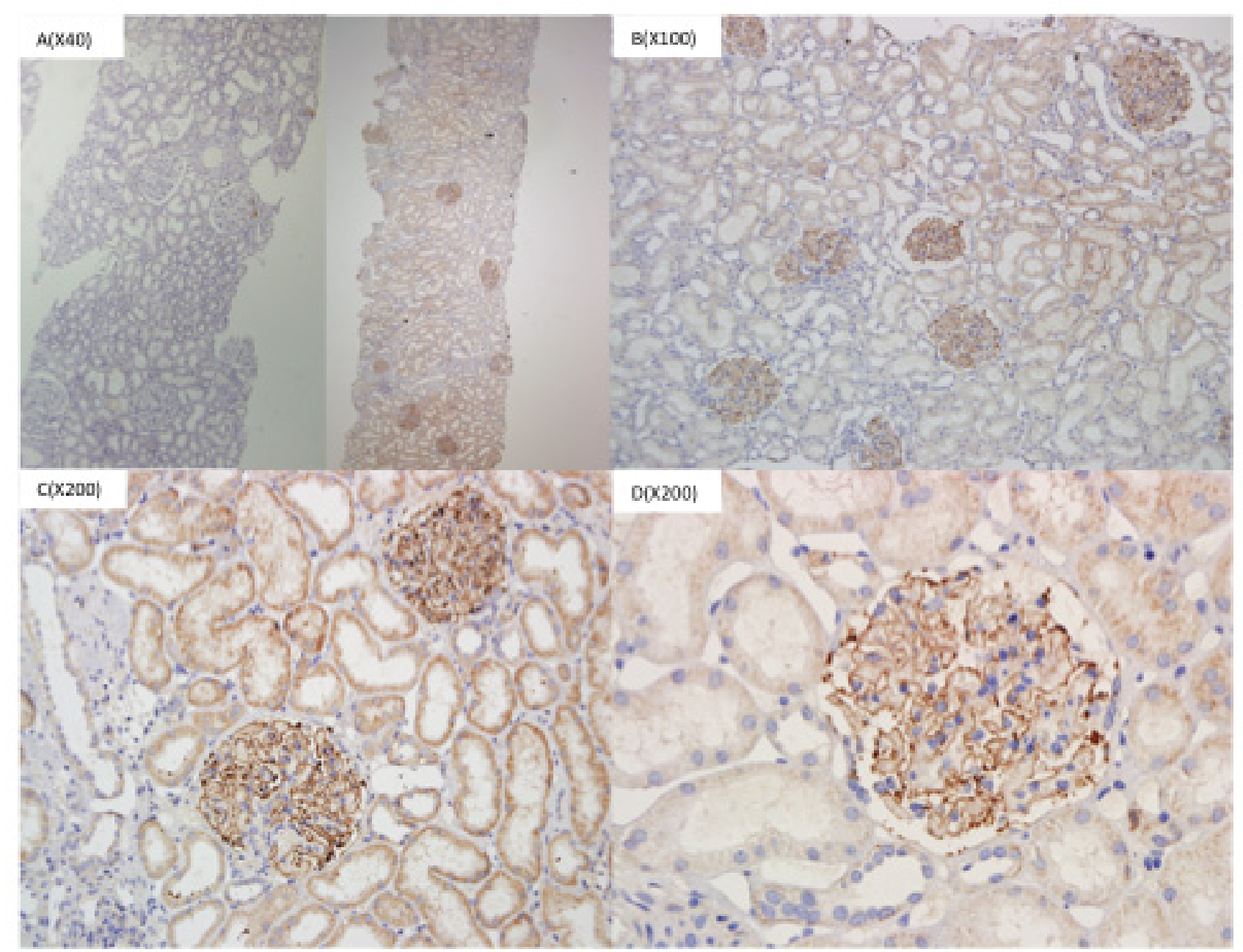

E

THSD7A-related MN1 THSD7A-related MN2 Heath control 1-50

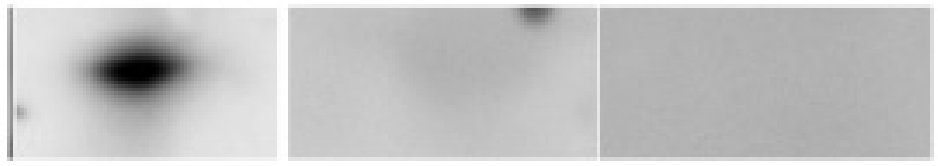

Figure 4: THSD7A in glomeruli and serum. Left: THASD7A negative glomeruli. Right: Strong global granular capillary loop THASD7A staining. Magnification $\times 40$ A., $\times 100$ B., $\times 200$ C. and $\times 400$ D. Western blotting to detect THSD7A in patient serum E. 
[30]. Because $\operatorname{PLA}_{2} \mathrm{R}$ and THSD7A play an essential role in the pathogenesis of $\mathrm{MN}$, the rates of anti-PLA $\mathrm{R}_{2}$ and anti-THSD7A positivity were significantly higher in $\mathrm{MN}$ patients than in other series. Consequently, in elderly patients and in patients in poor clinical condition or experiencing life-threatening complications, such as lung thrombus, kidney biopsy might be replaced with serological anti-PLA 2 R and anti-THSD7A detection for diagnosis of MN. We found that $17.64 \%$ patients had no circulating anti-PLA ${ }_{2} \mathrm{R}$, although $\mathrm{PLA}_{2} \mathrm{R}$ was detected in glomerular immune deposits. Thus, the absence of circulating $\mathrm{PLA}_{2} \mathrm{R}$ at the time of kidney biopsy did not rule out a diagnosis of $\mathrm{PLA}_{2} \mathrm{R}$-related $\mathrm{MN}$. We also identified five patients with circulating anti-PLA $R$, but without detectable $\mathrm{PLA}_{2} \mathrm{R}$ in glomerular deposits.

We found that $\mathrm{PLA}_{2} \mathrm{R}$ and THSD7A detection discriminated $\mathrm{MN}$ from other nephropathies, but could not distinguish secondary from primary MN. SMN in this study included patients with infections (hepatitis $\mathrm{B}$, hepatitis $\mathrm{C}$, syphilis), tumors, autoimmune diseases (psoriasis, Guillain-Barre syndrome), monoclonal gammopathy and interstitial nephritis. Lupus-associated MN patients were always PLA $\mathrm{R}_{2}$ negative. In SMN, the $P L A_{2} R$ positivity rate was $72.97 \%$; thus, $P_{2} A_{2} R$ in glomeruli and anti-PLA $R$ in circulation are not suitable for distinguishing IMN from SMN. Previous studies reported anti-PLA ${ }_{2} \mathrm{R}$ positivity in SMN cases in patients with HBV, lupus, tumors and. sarcoidosis $[10,14,18,32]$. One interpretation of these findings is that these patients had primary PLA2R-related MN causally unrelated to their additional pathologies. A second interpretation is that these systemic disease processes may activate the immune system to stimulate autoantibody production against $\mathrm{PLA}_{2} \mathrm{R}$. Therefore, whether or not PLA $\mathrm{A}_{2} \mathrm{R}$ can be used to differentiate IMN from SMN remains controversial.

Several recent studies correlated anti-PLA ${ }_{2} \mathrm{R}$ levels with clinical manifestations of disease status, specifically, decreasing anti-PLA ${ }_{2} \mathrm{R}$ during remission and increasing levels during relapse $[12,13,17,33-35]$. We found that anti-PLA $\mathrm{R}_{2}$ positive rates in patients with no remission were significant higher than in patients with CR or PR. Moreover, patients positive for anti-PLA $\mathrm{R}_{2} \mathrm{R}$ exhibited more severe proteinuria and lower albumin levels in contrast to patients negative for anti-PLA $\mathrm{R}_{2} \mathrm{at} \mathrm{MN}$ onset. Although baseline anti-PLA ${ }_{2} \mathrm{R}$ titers were lower in the remission group compared to no remission, the anti-PLA ${ }_{2} \mathrm{R}$ titer AUC for predicting no remission was 0.751 . There was no difference in remission rates between anti-PLA ${ }_{2} \mathrm{R}$-negative and -positive patients during follow-up. Similarly, remission rates were the same among patients with low, medium and high baseline anti-PLA 2 titers. Thus, anti$\mathrm{PLA}_{2} \mathrm{R}$ levels dynamically reflected disease status, but anti-PLA ${ }_{2} \mathrm{R}$ application as a predictive biomarker requires additional verification.

This study found that high urinary RBP levels might predict poor proteinuria outcome. AUC of urinary $\mathrm{RBP} / \mathrm{Cr}$ was 0.778 , which was higher than that of anti$\mathrm{PLA}_{2} \mathrm{R}$ titer. More patients with low or medium urinary RBP levels achieved remission as compared to those with high RBP. Another study reported that LMW urinary proteins predicted kidney function outcomes in $129 \mathrm{MN}$ patients [22]. AUCs were 0.81 and 0.81 for $\beta 2 \mathrm{~m}$ and $\alpha 1 \mathrm{~m}$, respectively, to predict a GFR increase of $25 \%$ from baseline.

Although anti-PLA ${ }_{2} \mathrm{R}$ titer may also be an early indicator of risk of progressive renal function loss $[12,13$, $17,26-28]$, in our study only two (1.42\%) patients showed an increase of $>25 \%$ baseline Scr and GFR reaching $<60$

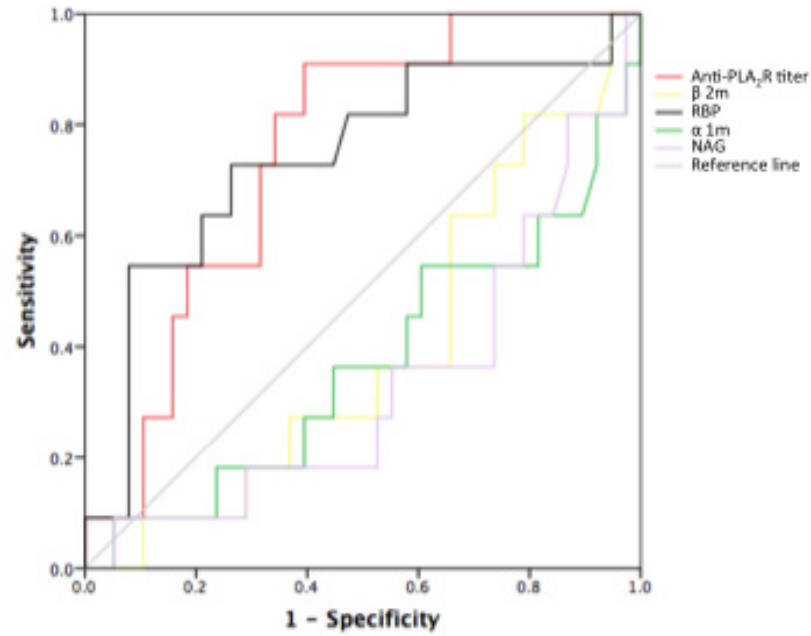

B

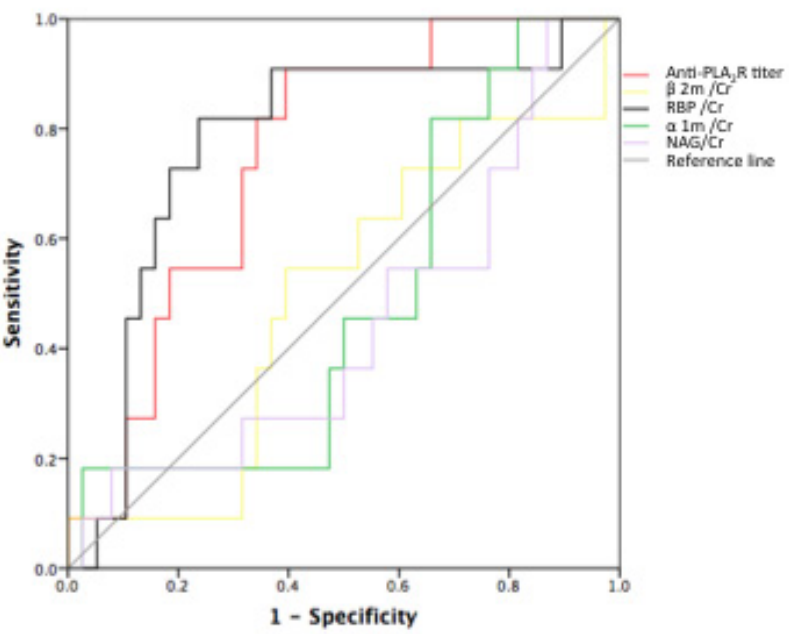

Figure 5: ROC curves for urinary excretion rates of LMW proteins and serum anti-PLA2R titer. AUCs for predicting no remission were as follows: anit-PLA 2 : 0.751 (0.608-0.895), $p=0.012 ; \mathrm{RBP}: 0.740$ (0.559-0.922), $p=0.016 ; \alpha 1 \mathrm{~m}: 0.370 ; \beta 2 \mathrm{~m}: 0.394$; NAG: $0.331 \mathrm{~A}$. AUCs corrected for urinary creatinine were as follows: RBP/Cr: $0.778(0.616-0.939), p=0.005 ; \alpha 1 \mathrm{~m} / \mathrm{Cr}: 0.483 ; \beta 2 \mathrm{~m} / \mathrm{Cr}$ : 0.495; NAG/Cr: 0.445 B. 
$\mathrm{ml} / \mathrm{min} / 1.73 \mathrm{~m}^{2}$ during follow-up. Since assessing renal function changes requires a longer period of observation time, we did not analyze correlations between biomarkers and loss of renal function. Our findings were limited by a relatively small study sample size and single-center patient recruitment. Besides, the observation time was relatively short. Further research with larger sample sizes and longer follow-up times are needed to validate $\mathrm{PLA}_{2} \mathrm{R}$ and urinary RBP sensitivities and utilities in diagnosing $\mathrm{MN}$.

In conclusion, we confirmed that anti-PLA $\mathrm{R}_{2}$ and anti-THSD7A were specifically detected in MN patient sera. Detection of PLA $\mathrm{A}_{2} \mathrm{R}$ THSD7A in kidney biopsies or of circulating anti-PLA ${ }_{2}$ R/anti-THSD7A can discriminate between MN and LN, but not between IMN and SMN. As a predictive index for proteinuria outcome, urinary RBP might be superior to serum anti-PLA 2 .

\section{MATERIALS AND METHODS}

\section{Patients and tissue samples}

In total, 315 patients were recruited between July 2012 and July 2014 from the Department of Nephrology, Ruijin Hospital, including 195 MN patients with confirmed renal biopsies, 70 non-MN nephrotic syndrome patients and 50 healthy controls. Serum samples from all $195 \mathrm{MN}$ patients were tested for antiPLA2R. Serum samples were collected cross-sectionally after treatments from 54 of these patients (Figure 1). Five of the 54 received ACEI/ARB (angiotensin converting enzyme inhibitors/angiotensin receptor blocker), two received steroid therapy, and 47 received steroids combined with immunosuppressive therapy ( 24 received cyclophosphamide, nine received cyclosporine, six received FK506, and eight received multi-target therapy) for varying lengths of time (1-123 months). The remaining 141 patients did not receive any $\mathrm{MN}$-specific treatments. Serum and urine samples were collected longitudinally from these patients at the time of renal biopsy, before any invasive treatments, and were followed up at 3, 6, 9, 12 and 30 months. Follow-up tests included 24-h proteinuria, serum albumin (Alb), serum creatinine (Scr) and other biochemical indicators. Among $136 \mathrm{MN}$ patients whose serum, urine and kidney tissue samples were available, 37 suffered SMN associated with hepatitis B (HBV), $n=11$; hepatitis $\mathrm{C}(\mathrm{HCV}), n=1$; syphilis, $n=2$; tumor $\mathrm{MN}, n=$ 8; psoriasis, $n=3$; Sjögren's syndrome, $n=2$; GuillainBarre syndrome, $n=1$; amyloidosis, $n=1$; monoclonal gammopathy, $n=1$; interstitial nephritis, $n=2$; diabetic nephropathy, $n=2$; hereditary $\mathrm{MN}, n=2$; and hepatitis $\mathrm{B}$ and tumor associated $\mathrm{MN}, n=1$. We also enrolled 18 class $\mathrm{V} \mathrm{LN}$ patients $(\mathrm{LN}-\mathrm{V}, n=1 ; \mathrm{LN}-\mathrm{IV}+\mathrm{V}, n=10 ; \mathrm{LN}-\mathrm{III}+\mathrm{V}$, $n=7)$.

\section{Study design}

$\mathrm{PLA}_{2} \mathrm{R}$-related $\mathrm{MN}$ was defined as being either positive for serum anti-PLA ${ }_{2} \mathrm{R}$ or glomerular $\mathrm{PLA}_{2} \mathrm{R}$ in biopsy-diagnosed MN. Similarly, THSD7A-related $\mathrm{MN}$ was defined as being either positive for serum antiTHSD7A or glomerular THSD7A in biopsy-diagnosed MN. Patients were divided into four groups depending on the presence of $\mathrm{PLA}_{2} \mathrm{R}$ antigen or its antibodies at the beginning of the study (Table 1). Presence of both circulating anti-PLA ${ }_{2} \mathrm{R}$ and glomerular $\mathrm{PLA}_{2} \mathrm{R}$ deposits was defined as group 1, presence of only glomerular $\mathrm{PLA}_{2} \mathrm{R}$ deposits or only circulating anti- $\mathrm{PLA}_{2} \mathrm{R}$ was defined as groups 2 and 3 , respectively, and negative for both was defined as group 4. Clinical characteristics such as 24-h proteinuria, album, Scr, remission rate, etc. at baseline and follow-up were compared among the four groups. Patients were divided into two groups according to disease status at the end of follow-up: remission and no remission. Urinary LMW proteins, including $\beta \mathrm{nm}$, urinary rinarurinary $\mathrm{RBP}$ and urinary $\mathrm{NAG}$, were compared between the two groups to assess the specificity and sensitivity of urinary biomarkers, measured at the time of renal biopsy, in predicting proteinuria prognosis. All participants were fully consenting adults, and the IRB board of Ruijin Hospital approved this study.

Antibody prevalence was calculated for each group and clinical parameters were compared between patients with and without anti-PLA ${ }_{2} \mathrm{R}$ antibodies. 24-h proteinuria and Scr were measured every three months. The study end point was defined as CR (complete remission) or PR (partial remission). PR was defined as stable renal function $(<25 \%$ increase in GFR calculated by modification of diet in renal disease equation) with a 24-h proteinuria of 0.3-3.5 g and a proteinuria reduction $\geq 50 \%$ compared to baseline. CR was defined as a $24-\mathrm{h}$ proteinuria $<0.3 \mathrm{~g}$ with stable renal function. Active disease was defined as a 24-h proteinuria $>3.5 \mathrm{~g}$, persistence of $>50 \%$ baseline proteinuria or $>25 \%$ increase in Scr.

\section{Serum anti-PLA $R$ and anti-THSD7A measurements}

Serum anti-PLA ${ }_{2} \mathrm{R}$ was assessed via indirect fluorescent antibody test (IFA) (FA1254-1005-50; EUROIMMUN AG, Lübeck, Germany). Serum was diluted 1:10 and anti-PLA ${ }_{2} \mathrm{R}$ detection was performed on an IFA Mosaic slide following the standard protocol. Serum anti-PLA ${ }_{2} \mathrm{R}$ titer was assessed via ELISA (Euroimmun, Lübeck, Germany; linearity: lower limit of detection $0.6 \mathrm{RU} / \mathrm{ml}$ ). A titer above $20 \mathrm{RU} / \mathrm{ml}$ was defined anti-PLA2R positive. Serum nti-THSD7A was detected by western blot. Recombinant THSD7A (Atlas Antibodies $\mathrm{AB}$, Stockholm, Sweden) was electrophoresed under non-reducing conditions and proteins were transferred to 
nitrocellulose membranes according to standard protocols. Blots were blocked with $10 \%$ milk in Tris-buffered normal saline-Tween 20 (TBS-T). For the primary antibody, patient serum was diluted at a 1:100 ratio and incubated with blots overnight at $4^{\circ} \mathrm{C}$. Peroxidase-conjugated donkey anti-human IgG (Euroimmun, Lübeck, Germany) was used as the secondary antibody at $4^{\circ} \mathrm{C}$. Blots were incubated in chemiluminescent substrate, exposed to photographic film for $5 \mathrm{~s}$ to $2 \mathrm{~min}$ and developed in a Kodak X-Omat developer.

\section{Histological measurements}

Renal biopsies were incubated with a rabbit polyclonal anti-PLA 2 antibody (Atlas Antibodies $\mathrm{AB}$, Stockholm, Sweden). PLA 2 R staining quality was evaluated by standard immunofluorescence microscopy. The presence of granular capillary loop staining in glomeruli was defined as positive, and the absence was negative. Each section was scored on a scale of $0-3+$. A positive THSD7A immunohistochemical result was defined as strong diffuse global granular staining along capillary loops [21]. Interstitial fibrosis was assessed categorically as minor, moderate or extensive. Histological results were confirmed by two pathologists independently.

\section{Urinary measurements}

Urinary $\alpha 1 \mathrm{~m}$ levels were measured by rate scatter nephelometry on a BN II automatic protein analyzer nephelometer (Siemens, Germany), urinary $\beta 2 \mathrm{~m}$ by chemiluminescence on an Immulite2000 immunoassay system (Siemens, Germany), urinary RBP by Immune turbidimetry on a UniCel DxC800 Access immunoassay system (Beckman, USA) and urinary NAG by colorimetry on a UniCel DxC800 (Beckman, USA).

\section{Statistical analysis}

For descriptive statistics, data were presented as means ( \pm standard deviation) or medians (range) as appropriate. Kruskall-Wallis tests were used for comparisons among the four groups classified by serum anti-PLA $\mathrm{A}_{2} \mathrm{R}$ and glomerular $\mathrm{PLA}_{2} \mathrm{R}$ levels. Proportions were compared by Chi-square analysis. Time to remission was assessed using the Kaplan-Meier method. A multivariate Cox regression analysis was conducted to identify potential risk factors associated with the development of active disease in this patient cohort. Clinical factors, including age, sex, PLA 2 R-related $\mathrm{MN}$, anti-PLA $\mathrm{R}_{2}$ levels, proteinuria, serum albumin, Scr, cholesterol, triglycerides, glomerular lesions and interstitial fibrosis at renal biopsy were adjusted in the Cox model. Correlations were assessed via Spearman
Rank test. Receiver operating characteristic (ROC) curve was used to determine cut-off values for urinary predictors of proteinuria remission. All statistical analyses were performed using SPSS (version 17.0, SPPS Inc., Chicago, IL, USA). $\mathrm{P}<0.05$ was considered statistically significant.

\section{CONFLICTS OF INTEREST}

The authors disclose no conflicts of interest.

\section{GRANT SUPPORT}

This work was supported by grants from the National Basic Research Program of China 973, grant no. 2012CB517600 (no. 2012CB517604), Projects of Shanghai Science and Technology Committee (grant No.14430721000), Translational medicine collaborative innovation cooperation research projects of School of Medicine, Shanghai Jiaotong University (grant No.2015273), National national natural science foundation of China (grant No. 15ZR1426300).

\section{REFERENCES}

1. Beck LH, Jr. and Salant DJ. Membranous nephropathy: from models to man. The Journal of clinical investigation. 2014; 124:2307-2314.

2. Pan X, Xu J, Ren H, Zhang W, Xu Y, Shen P, Li X, Wang W, Chen X, Wu P, Feng X, Hao C and Chen N. Changing spectrum of biopsy-proven primary glomerular diseases over the past 15 years: a single-center study in China. Contributions to nephrology. 2013; 181:22-30.

3. Xie $\mathrm{J}$ and Chen N. Primary glomerulonephritis in mainland China: an overview. Contributions to nephrology. 2013; 181:1-11.

4. Lefaucheur C, Stengel B, Nochy D, Martel P, Hill GS, Jacquot C, Rossert J and Group G-PS. Membranous nephropathy and cancer: Epidemiologic evidence and determinants of high-risk cancer association. Kidney international. 2006; 70:1510-1517.

5. Zeng CH, Chen HM, Wang RS, Chen Y, Zhang SH, Liu L, Li LS and Liu ZH. Etiology and clinical characteristics of membranous nephropathy in Chinese patients. Am J Kidney Dis. 2008; 52:691-698.

6. Zhonglin Feng SW, Yanlin Huang, Xinling Liang, Wei Shi, Bin and Zhang. A follow-up analysis of positron emission tomography: computed tomography in detecting hidden malignancies at the time of diagnosis of membranous nephropathy. Oncotarget. 2016; 7:9645-9651. doi: 10.18632/oncotarget.7506.

7. Beck LH, Jr., Bonegio RG, Lambeau G, Beck DM, Powell DW, Cummins TD, Klein JB and Salant DJ. M-type phospholipase A2 receptor as target antigen in idiopathic membranous nephropathy. The New England journal of medicine. 2009; 361:11-21. 
8. Hofstra JM, Beck LH, Jr., Beck DM, Wetzels JF and Salant DJ. Anti-phospholipase A(2) receptor antibodies correlate with clinical status in idiopathic membranous nephropathy. Clinical journal of the American Society of Nephrology. 2011; 6:1286-1291.

9. Hoxha E, Harendza S, Zahner G, Panzer U, Steinmetz O, Fechner K, Helmchen $U$ and Stahl RA. An immunofluorescence test for phospholipase-A(2)-receptor antibodies and its clinical usefulness in patients with membranous glomerulonephritis. Nephrology, dialysis, transplantation. 2011; 26:2526-2532.

10. Qin W, Beck LH, Jr., Zeng C, Chen Z, Li S, Zuo K, Salant DJ and Liu Z. Anti-phospholipase A2 receptor antibody in membranous nephropathy. Journal of the American Society of Nephrology. 2011; 22:1137-1143.

11. Hofstra JM, Debiec H, Short CD, Pelle T, Kleta R, Mathieson PW, Ronco P, Brenchley PE and Wetzels JF. Antiphospholipase A2 receptor antibody titer and subclass in idiopathic membranous nephropathy. Journal of the American Society of Nephrology. 2012; 23:1735-1743.

12. Hoxha E, Kneissler U, Stege G, Zahner G, Thiele I, Panzer U, Harendza S, Helmchen UM and Stahl RA. Enhanced expression of the M-type phospholipase A2 receptor in glomeruli correlates with serum receptor antibodies in primary membranous nephropathy. Kidney international. 2012; 82:797-804.

13. Kanigicherla D, Gummadova J, McKenzie EA, Roberts SA, Harris S, Nikam M, Poulton K, McWilliam L, Short CD, Venning M and Brenchley PE. Anti-PLA2R antibodies measured by ELISA predict long-term outcome in a prevalent population of patients with idiopathic membranous nephropathy. Kidney international. 2013; 83:940-948.

14. Oh YJ, Yang SH, Kim DK, Kang SW and Kim YS. Autoantibodies against phospholipase A2 receptor in Korean patients with membranous nephropathy. PloS one. 2013; 8:e62151.

15. Kao L, Lam V, Waldman M, Glassock RJ and Zhu Q. Identification of the Immunodominant Epitope Region in Phospholipase A2 Receptor-Mediating Autoantibody Binding in Idiopathic Membranous Nephropathy. Journal of the American Society of Nephrology. 2014.

16. Schlumberger W, Hornig N, Lange S, Probst C, Komorowski L, Fechner K, Dahnrich C and Stocker W. Differential diagnosis of membranous nephropathy with autoantibodies to phospholipase A2 receptor 1 . Autoimmunity reviews. 2014; 13:108-113.

17. Segarra-Medrano A, Jatem-Escalante E, Quiles-Perez MT, Salcedo MT, Arbos-Via MA, Ostos H, Valtierra N, Carnicer-Caceres C and Agraz-Pamplona I. Prevalence, diagnostic value and clinical characteristics associated with the presence of circulating levels and renal deposits of antibodies against the M-type phospholipase A2 receptor in idiopathic membranous nephropathy. Nefrologia. 2014; 34:353-359.
18. Stehle T, Audard V, Ronco P and Debiec H. Phospholipase A2 receptor and sarcoidosis-associated membranous nephropathy. Nephrology, dialysis, transplantation. 2015; 30:1047-1050.

19. Gödel M, Grahammer F, Huber TB. Thrombospondin type-1 domain-containing 7A in idiopathic membranous nephropathy. N Engl J Med. 2014; 371:2277-2287.

20. Iwakura T, Ohashi N, Kato A, Baba S and Yasuda H. Prevalence of Enhanced Granular Expression of Thrombospondin Type-1 Domain-Containing 7A in the Glomeruli of Japanese Patients with Idiopathic Membranous Nephropathy. PloS one. 2015; 10:e138841.

21. Larsen CP, Cossey LN and Beck LH. THSD7A staining of membranous glomerulopathy in clinical practice reveals cases with dual autoantibody positivity. Mod Pathol. 2016; 29:421-426.

22. van den Brand JA, Hofstra JM and Wetzels JF. Lowmolecular-weight proteins as prognostic markers in idiopathic membranous nephropathy. Clinical journal of the American Society of Nephrology. 2011; 6:2846-2853.

23. van den Brand JA, Hofstra JM and Wetzels JF. Prognostic value of risk score and urinary markers in idiopathic membranous nephropathy. Clinical journal of the American Society of Nephrology. 2012; 7:1242-1248.

24. Bazzi C, Rizza V, Casellato D, Tofik R, Berg AL, Gallieni M, D'Amico G and Bakoush O. Fractional excretion of IgG in idiopathic membranous nephropathy with nephrotic syndrome: a predictive marker of risk and drug responsiveness. BMC Nephrol. 2014; 15:74.

25. Debiec $\mathrm{H}$ and Ronco $\mathrm{P}$. Immunopathogenesis of membranous nephropathy: an update. Seminars in immunopathology. 2014; 36:381-397.

26. Meyer-Schwesinger $C$, Lambeau $G$ and Stahl RA. Thrombospondin type-1 domain-containing 7A in idiopathic membranous nephropathy. The New England journal of medicine. 2015; 372:1074-1075.

27. Beck LH, Jr., Fervenza FC, Beck DM, Bonegio RG, Malik FA, Erickson SB, Cosio FG, Cattran DC and Salant DJ. Rituximab-induced depletion of anti-PLA2R autoantibodies predicts response in membranous nephropathy. Journal of the American Society of Nephrology. 2011; 22:1543-1550.

28. Bruschi M, Carnevali ML, Murtas C, Candiano G, Petretto A, Prunotto M, Gatti R, Argentiero L, Magistroni R, Garibotto G, Scolari F, Ravani P, Gesualdo L, Allegri L and Ghiggeri GM. Direct characterization of target podocyte antigens and auto-antibodies in human membranous glomerulonephritis: Alfa-enolase and borderline antigens. Journal of proteomics. 2011; 74:2008-2017.

29. Stanescu HC, Arcos-Burgos M, Medlar A, Bockenhauer D, Kottgen A, Dragomirescu L, Voinescu C, Patel N, Pearce K, Hubank M, Stephens HA, Laundy V, Padmanabhan S, et al. Risk HLA-DQA1 and PLA(2)R1 alleles in idiopathic membranous nephropathy. N Engl J Med. 2011; 364:616626. 
30. Lv J, Hou W, Zhou X, Liu G, Zhou F, Zhao N, Hou P, Zhao $\mathrm{M}$ and Zhang $\mathrm{H}$. Interaction between PLA2R1 and HLADQA1 variants associates with anti-PLA2R antibodies and membranous nephropathy. Journal of the American Society of Nephrology. 2013; 24:1323-1329.

31. Fresquet M, Jowitt TA, Gummadova J, Collins R, O'Cualain R, McKenzie EA, Lennon R and Brenchley PE. Identification of a Major Epitope Recognized by PLA2R Autoantibodies in Primary Membranous Nephropathy. Journal of the American Society of Nephrology. 2014.

32. Xie QH LY, Hao CM. Renal PLA2R in hepatitis B virus - associated membranous nephropathy. Philadelphia, PA, USA. 2014.

33. Du Y, Li J, He F, Lv Y, Liu W, Wu P, Huang J, Wei S and Gao H. The diagnosis accuracy of PLA2R-AB in the diagnosis of idiopathic membranous nephropathy: a metaanalysis. PloS one. 2014; 9:e104936.
34. Elion Hoxha1 SH, Hans Pinnschmidt2, Ulf Panzer1, Rolf A. K. Stahl1*. PLA2R Antibody Levels and Clinical Outcome in Patients with Membranous Nephropathy and Non-Nephrotic Range Proteinuria under Treatment with Inhibitors of the Renin-Angiotensin System. PLoS ONE. 2014; 9:e110681.

35. Segarra-Medrano A, Jatem-Escalante E, Carnicer-Caceres C, Agraz-Pamplona I, Salcedo MT, Valtierra N, OstosRoldan E, Arredondo KV and Jaramillo J. Evolution of antibody titre against the M-type phospholipase A2 receptor and clinical response in idiopathic membranous nephropathy patients treated with tacrolimus. Nefrologia. 2014; 34:491-497. 